- from practical application. Joy Goswami, assistant director of the technology-transfer office at the University of Delaware in Newark, estimates that only about $5 \%$ of patents are licensed at most universities. The rest are a drain on office resources, he adds, because of required maintenance and legal fees.

Earlier this month, at a meeting of the Association of University Technology Managers in Boston, Massachusetts, Goswami led a discussion on how to unload the $95 \%$ of patents that remain unlicensed. One option is to use a broker or auction house that specializes in trading intellectual property. It is a controversial solution that some universities are afraid to touch. "When you go to sell a patent, the university loses any ability to ensure that it's being managed in the public's best interest," says Kelly Sexton, head of the technology-transfer office at North Carolina State University in Raleigh, which licenses out a relatively robust $15 \%$ of its patents.

Thomas Major, vice-president of IPOfferings, a patent-broker firm based in Boca Raton, Florida, does not understand the hesitation. He spent nine years managing intellectual property at the University of Utah in Salt Lake City, and says that universities would be foolhardy to ignore auction houses. "When I was at the University of Utah, I would have sold those patents in a heartbeat," he says.

Major says that IPOfferings has handled about 20 patents from universities over the past 3 years - roughly $7 \%$ of the firm's total business. James Malackowski, chief executive of Ocean Tomo in Chicago, Illinois, a company best known for its patent auctions, says that universities are increasingly coming to him, and represent nearly $20 \%$ of his business. Both Major and Malackowski say that their firms can place limits on who can buy or exclusively license a patent. Even so, Major says that at least one of his university clients abandoned that request after seeing how much a patent aggregator was willing to pay. "In the end, it just came down to money."

Such decisions violate the spirit of a 2007 memo endorsed by more than 100 institutions. Offering guidance for ethical patent licensing, it cites the risks of dealing with patent aggregators. Yet the signatories include Caltech and three other universities that have licensed patents to Intellectual Ventures, according to Feldman's research: Duke University in Durham, North Carolina; the University of Florida in Gainesville; and the University of Ottawa in Canada. The universities declined to comment on the patent deals.

Caltech mathematician Peter Schröder, one of the three inventors on US patent $7,023,435$, is not too bothered. He would be troubled, he says, if Intellectual Ventures were using his patent to harass other companies, but so far he has not heard of that happening. "It's not giving me heartache," he says. -

\section{Mozilla plan seeks to debug scientific code}

\section{BY ERIKA CHECK HAYDEN}

$\mathrm{W}$ hen ecologist Carl Boettiger wrote a blog post in June calling for greater stringency in the peer review of scientific software in research papers, he hardly expected to stir up controversy. But in 54 comments on the post, researchers have debated how detailed such reviews should be; one said that it was a "trifle arrogant" of Boettiger, of the University of California at Santa Cruz, to insist that computer code attain his stringent standards before publication.

Now an offshoot of the Internet non-profit organization Mozilla has entered the debate, aiming to discover whether a review process could improve the quality of researcher-built software that is used in myriad fields today, ranging from ecology and biology to social science. In an experiment being run by the Mozilla Science Lab, software engineers have reviewed selected pieces of code from published papers in computa-
"One worry is that scientists will be even more discouraged from publishing their code." tional biology. "Scientific code does not have that comprehensive, off-the-shelf nature that we want to be associated with the way science is published and presented, and this is our attempt to poke at that issue," says Mozilla Science Lab director Kaitlin Thaney.

Researchers increasingly rely on computation to perform tasks at every level of science, but most do not receive formal training in coding best practice. That has led to high-profile problems. Some scientists have argued, for example, that the fraudulent findings used as the basis for clinical trials in 2007 would have been exposed much earlier if cancer researcher Anil Potti of Duke University in Durham, North Carolina, had been compelled to publish his data and computer code along with his original papers.

More routinely, incorrect or slipshod code prevents other researchers from replicating work, and can even lead them astray. In 2006, Geoffrey Chang of the Scripps Research Institute in La Jolla, California, had to retract five research papers on crystal structure after finding a simple error in the code he was using, which had been provided by another lab. "That's the kind of thing that should freak any scientist out," says computational biologist Titus Brown at Michigan State University in East Lansing. "We don't have good processes in place to detect that kind of thing in software."

Mozilla is testing one potential process, deploying the type of code review that is routinely used on commercial software before it is released. Thaney says that the procedure is much like scientific peer review: "The reader looks for everything, from the equivalent of grammar and spelling to the correctness of the logic." In this case, Mozilla opted to examine nine papers from PLoS Computational Biology that were selected by the journal's editors in August. The reviewers looked at snippets of code up to 200 lines long that were included in the papers and written in widely used programming languages, such as R, Python and Perl.

The Mozilla engineers have discussed their findings with the papers' authors, who can now choose what, if anything, to do with the markups - including whether to permit disclosure of the results. Those findings will not affect the status of their publications, says Marian Petre, a computer scientist at the Open University in Milton Keynes, UK, who will debrief the reviewers and authors. Thaney expects to release a preliminary report on the project within the next few weeks.

Computational biologists are betting that the engineers will have found much to criticize in the scientific programming, but will also have learnt from the project. They may have been forced to brush up on their biology, lest they misunderstood the scientific objective of the code they were examining, Brown says.

Theo Bloom, editorial director for biology at non-profit publisher PLoS, shares that expectation, but says such reviews may still be useful, even if the Mozilla reviewers lack biological expertise. Yet that would prompt another question: how can journals conduct this type of review in a sustainable way?

The time and skill involved may justify paying reviewers, just as statistical reviewers of large clinical trials are paid. But researchers say that having software reviewers looking over their shoulder might backfire. "One worry I have is that, with reviews like this, scientists will be even more discouraged from publishing their code," says biostatistician Roger Peng at the Johns Hopkins Bloomberg School of Public Health in Baltimore, Maryland. "We need to get more code out there, not improve how it looks." - 